fundamental process one is able to identify the organisational drivers of accidents \& losses. This understanding allows for the modification of systems, processes \& procedures that affect, structural changes that permanently eliminate the core drivers of loss, \& enhance the company's bottom line.

Attendees will be able to take away an outline of how to link the undesirable side effects to some of the inputs and thereby achieve a tailored, integrated, multi-strategy initiative that will result in a high performance safety management system, resulting in lower losses \& improved profitability.

\title{
0057 THE UNWRITTEN ORGANISATIONAL RULES OF ENGAGEMENT
}

P G Furst* Correspondence: Liberty Mutual Insurance Company, 12657 Alcosta Bulevard San Ramon, CA 94507, USA

10.1136/ip.2010.029215.57

Henri Feyol proposed fundamental precepts of management, since then many different theories \& interventions have been tried to improve results but with mixed outcomes. The question is what is it that occurs within our organisations that creates barriers to achieving stellar results?

If you think about it, in every realm of our lives there are rules of engagement. These rules apply at work, in our social as well as family life. If we further think about it, these rules come in two varieties, a written \& an unwritten form. The written rules are how we are supposed to act \& the unwritten ones are the way we actually do act. These unwritten rules help employees cope \& successfully function within complex organisations. Unwritten rules tend to have side effects some of which are undesirable (accidents \& losses).

The undesirable side effects result from the interaction of the written rules, managements actions \& behaviours as well as the employees reaction to them. In understanding this 